\title{
Strip yield modelling of fatigue crack under variable amplitude loading
}

\author{
Konjengbam Darunkumar Singh ${ }^{1 *}$, Yigeng $\mathrm{Xu}^{2}$ and Ian Sinclair $^{3}$ \\ ${ }^{1}$ Department of Civil Engineering, Indian Institute of Technology Guwahati, India \\ ${ }^{2}$ School of Aerospace, Automotive and Design Engineering, University of Hertfordshire, UK \\ ${ }^{3}$ Materials Research Group, School of Engineering Sciences, University of Southampton, Southampton, U.K.
}

(Manuscript Received 000 0, 2009; Revised 000 0, 2009; Accepted 000 0, 2009) -please leave blank

\begin{abstract}
The results from 'strip yield' approach of the FASTRAN type models of plasticity induced crack closure effects of fatigue cracks subjected to variable amplitude loadings are presented. The strip yield results are compared with authors' finite element (FE) and experimental results. It has been observed that the strip yield model is seen to be fundamentally limited by choice of $\alpha$ (constraint factor) and corresponding to treat baseline closure effects. Double overload closure behavior is functionally similar for both strip yield and FE models. Under multiple overloads, an important functional difference is seen between FE and strip yield models. This has been linked to the absence of in-plane constraint in the strip yield model, which is seen to have a distinct decreasing influence on on-going closure effects.
\end{abstract}

Keywords: Fatigue; Variable amplitude loading; Strip yield modelling; Finite element modelling.

\section{Introduction}

For many fatigue critical structural components, fatigue crack propagation under real service conditions involves variable amplitude (VA) loading rather than constant cyclic load amplitudes. Irregularities in fatigue loading are well known to result in transient effects in crack growth [1-3]. An understanding of fatigue behavior under VA load histories may of course then help in the design and safe operation of damage tolerant structural components. Numerous attempts have been made to understand fatigue behavior under simple single overload transients [2,4-10]. For an understanding on fatigue crack response during realistic service loads, the effects of periodic overloads (dual or multiple, isolated or block) have been investigated [3, 11-28]. When successive (or periodic) overloads are applied between periods of constant amplitude fatigue loading, there arises the potential for overload interaction. [21], for example, observed an apparent dependence of interactions between repeated overloads on the interval between the overloads. Closely spaced overloads may of course ultimately lead to acceleration rather than retardation of crack growth as crack acceleration at each overload may exceed the retardation in the subsequent baseline cycles. Conversely, in cases of infrequently applied overloads,

*Corresponding author. Tel +91 361258 2423; Fax +91 3612582440 Email address: darun@iitg.ernet.in (Konjengbam Darunkumar Singh) interactions may of course be expected to become small. However, there may be a range of overload spacing for which retardation effects are reported to be enhanced [11, $12,15,17,18,21,24]$.

While most studies made on reported periodic overloads are based on experimental approaches, a few finite element (FE) and analytical studies exist, particularly for plane stress situations, $[10,17,20,25,29] . \quad[20,25]$ suggest an increase in crack closure levels with ongoing crack propagation, which then appears to stabilize to a 'plateau' level. [17] studied deformation characteristics of periodic overloads and found that differential surface profiles (differences in crack surface displacements after and before overloads) increased with decreasing separation of overloads. It is appropriate to note that to the best of the authors' knowledge only authors' reports [10, 29] have been found on plane strain FE analyses subjected to periodic overloads with emphasis on the effect of overload spacing on closure levels. In the analytical front, several attempts have been reported to model PICC (plasticity induced crack closure) effects by modifying the established Dugdale strip yield model [30] to leave plastically deformed material in a propagating crack wake [31-33]. Such models are essentially applicable to plane stress analyses, without considering threedimensional constraint on closure behavior. An attempt 


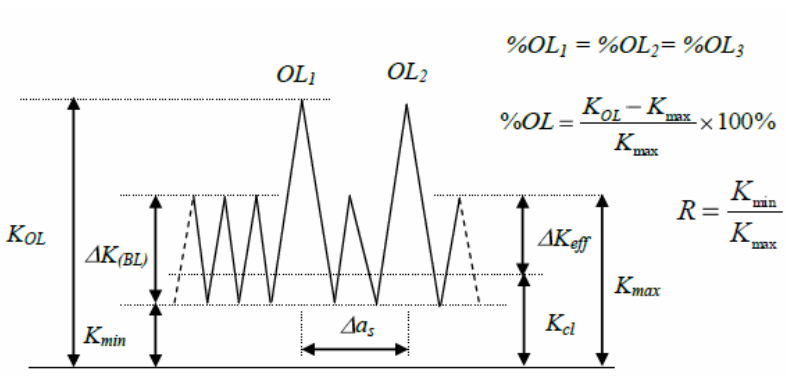

Fig. 1. Schematic illustration of the nomenclature adopted for repeated overloads analyses (single spike loading for single overload analyses).

was made by [34] to study both plane stress and plane strain closure behavior using a similar modified Dugdale model, by introducing a 'constraint factor' (essentially a fitting parameter) on tensile yielding to account for such three-dimensional effects (incorporated in their FASTRAN code [23]. Newman's FASTRAN calculations have been implemented and additional modifications made to include roughness induced crack closure (RICC) effects by [35] and [36]: to differentiate Xu's code from Newman's original model, Xu's code will be referred to as a 'strip yield model'. In the first instance, this strip yield approach is used in the present analysis to study the effects of PICC on VA loadings. The analysis results are then compared with authors' FE [10, 29] and experimental [35] results, for comparable model parameters. The work at present only considers repetitive (identical) overloads, as illustrated in Fig. 1 where $\left(\Delta a_{s}=\right.$ overload spacing distance; and $\Delta N_{s}=$ loading cycles separating overloads). Fig. 1 shows schematically the nomenclature adopted for periodic overloads analysis, where the baseline stress intensity factor (SIF) range, $\Delta K_{(B L)}=K_{\max }-$ $K_{\min }, K_{\max }$ and $K_{\min }$ are the maximum and minimum SIF respectively, $K_{O L}$ is the overload SIF; the percentage overload, \%OL $=\left(\left(K_{O L}-K_{\max }\right) / K_{\max }\right) \times 100 \%$; the closure level, $K_{c l}$; the effective SIF range, $\Delta K_{(e f f)}=K_{\max }-$ $K_{c l}$; the applied SIF range, $\Delta K_{(a p p)}=K_{\max }-K_{\min }$; the load ratio, $R=K_{\min } / K_{\max }$; and the crack closure, $K_{c l} / K_{\max }=1$ $(1-R) U$ (where $\left.U=\Delta K_{(e f f)} / \Delta K_{(a p p)}\right)$. The strip yield, FE and experimental techniques used are briefly described below.

\section{Analysis procedures}

\section{- $\quad$ Strip yield modelling}

In Newman's models the plastic region near the crack tip and the residual plastic deformation region along the crack surfaces were considered to be composed of rigidperfectly plastic bar elements with a flow stress $\sigma_{o}$, which is the average between the yield stress $\left(\sigma_{y}\right)$ and the ultimate tensile strength $\left(\sigma_{U T S}\right)$. When stress is applied, the bar elements are either intact (in the plastic zone) or broken (residual plastic deformation), with broken elements only being able to carry compressive loads

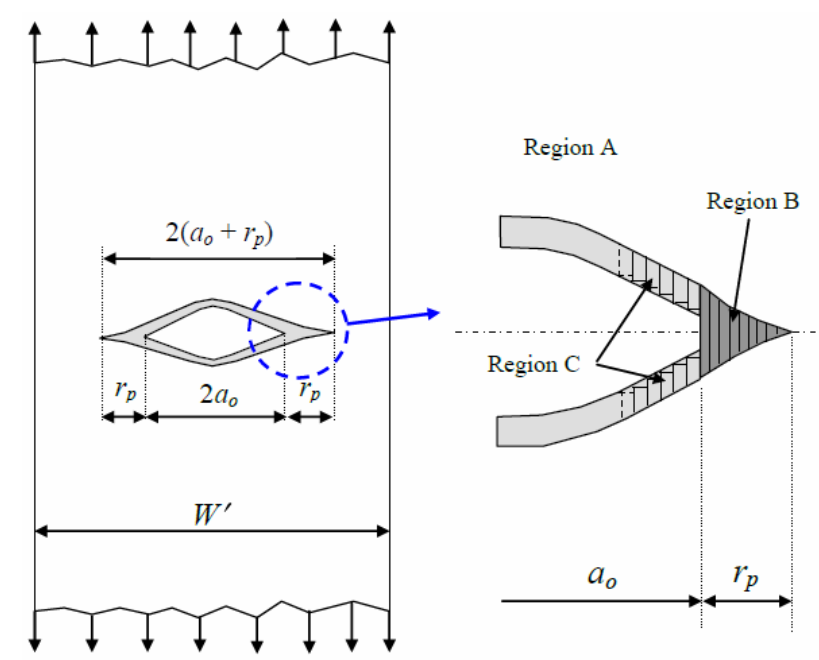

$\sigma$

Fig. 2a. Schematic diagram of the CCT specimen showing Dugdale type residual plastic deformations, identifying linear elastic region (Region A), plastic region ahead of the crack tip (Region B) and residual plastic deformation region along the crack surfaces (Region C) (after Newman, 1981 and Xu, 2001).

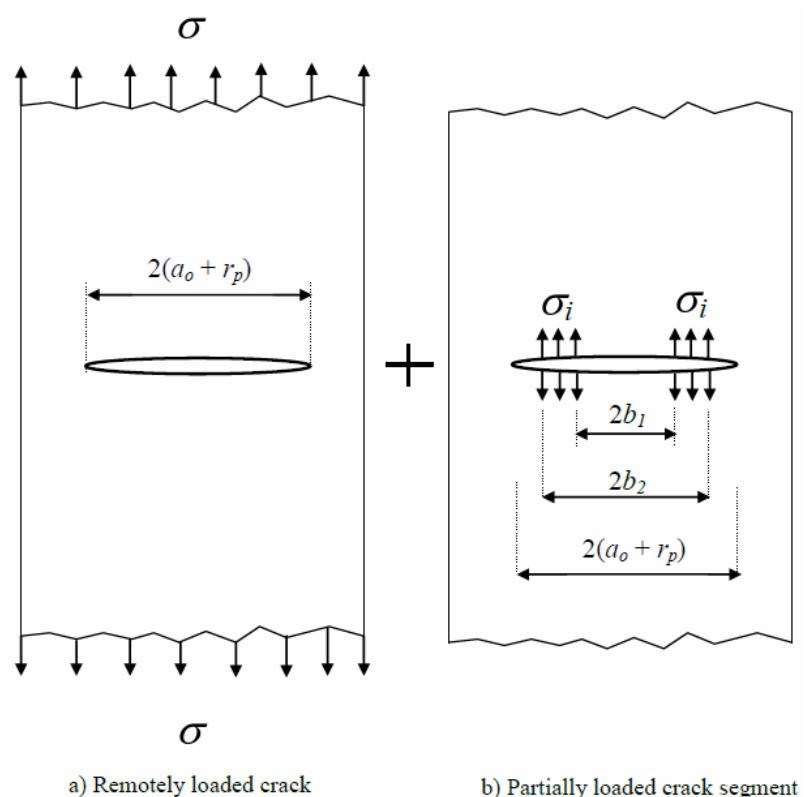

Fig. 2b: Schematic diagram showing superposition of two elastic problems of a CCT specimen subjected to a) remote uniform tensile stress $(\sigma)$ and b) uniform stress $\left(\sigma_{i}\right)$ over a segment of the crack surface (after Newman, 1981 and $\mathrm{Xu}, 2001)$.

(when they are in contact). Elements that are not in contact do not affect the calculation of crack-surface displacements. The crack opening stresses are computed numerically by solving the boundary value problem. A constraint factor, $\alpha$, is used to elevate the crack tip flow stress $\left(\alpha \sigma_{o}\right)$ to notionally account for the influence of stress state on plastic-zone size and crack-surface displacements. For plane stress conditions $\alpha$ is equal to unity (original Dugdale model), but equal to 3 for simulated plane strain conditions. Based on 3D FE analyses, 
[37] found that the 'global constraint factor', $\alpha_{g}$ (defined as the ratio of average normal stress in the plastically deformed material to the flow stress) rapidly drops as $K$ levels increase (plastic zone size increases) and approaches a value near the plane stress limit $(\sim 1.0)$. The performance of such models in practice is found to depend on the correct estimation of $\alpha$, which in effect becomes a fitting parameter as explicit descriptions of mixed stress states and $\alpha_{g}$ are not available. Mathematical formulations of the strip yield model are given in detail elsewhere in the literature $[34,35]$. The basic approach of strip yield model formulation is described below.

The strip yield model considers a CCP (center cracked plate) specimen subjected to uniform applied stress (Fig. 2a). It is assumed that all plastic deformation is contained within a thin strip along the crack line. Thus the specimen is composed of three regions:

1. Region $\mathrm{A}$ : a linear elastic region containing a fictitious crack of length $2\left(a_{o}+r_{p}\right)$. This is

2. Region B: a plastic region of length $r_{p}$ ahead of the crack tip, and

3. Region $\mathrm{C}$ : a residual plastic deformation region of length $a_{o}$.

The material within regions $\mathrm{B}$ and $\mathrm{C}$ is represented by a series of finite-width rigid-perfectly plastic bar elements with flow stress $\sigma_{o}$. On applying a stress, these bar elements are either intact (in the plastic zone, region B) or broken (in the residual plastic deformation region, region $\mathrm{C}$ ). Elements in region $\mathrm{B}$ can carry both tensile and compressive stresses, while the crack wake elements (in region $\mathrm{C}$ ) in contact can only carry compressive stresses and yield at $-\sigma_{o}$. The plastic zone size and crack surface displacements are computed by superposition of two elastic problems, viz., a crack in a finite-width plate subjected to either:

1. Remote uniform stress $(\sigma)$ or

2. Uniform stress applied over a segment of the crack surface (see Fig. 2b).

The crack opening stress $\left(\sigma_{o p}\right)$ may be calculated either from:

1. Displacement analysis: by defining the applied stress required to fully open the crack surfaces to be $\sigma_{o p}[23]$ or

2. Contact stress analysis: the applied stress intensity factor at $\sigma_{o p}$ is equated to the stress intensity factor caused by the contact stresses at the minimum stress, $\sigma_{\min }[22,33,34,38]$.

Regions $\mathrm{B}$ and $\mathrm{C}$ are modelled using a fixed number of elastic-perfectly plastic elements (100 is chosen), as shown schematically in Fig. 2a. 60 elements are used for region $\mathrm{C}$ and 40 elements for region $\mathrm{B}$, the element

Table 1: Alloy compositions (wt \%)

\begin{tabular}{|c|c|c|c|c|c|}
\hline Aluminium alloy & $\mathrm{Cu}$ & $\mathrm{Mg}$ & $\mathrm{Mn}$ & $\mathrm{Fe}$ & $\mathrm{Si}$ \\
\hline 2024-T351 & 4.06 & 1.36 & 0.54 & 0.20 & 0.12 \\
\hline 2024A-T351 & 4.51 & 1.44 & 0.33 & 0.16 & 0.05 \\
\hline
\end{tabular}

Table 2: Material properties of the alloys

\begin{tabular}{|c|c|c|c|}
\hline Aluminium alloy & $\sigma_{y}(\mathrm{MPa})$ & $\sigma_{U T S}(\mathrm{MPa})$ & Elongation $(\%)$ \\
\hline 2024-T351 & 372 & 483 & 21.4 \\
\hline 2024A-T351 & 345 & 434 & 25.2 \\
\hline
\end{tabular}

widths being varied with their relative positions, with finer elements concentrated around the physical crack tip and behind the fictitious crack tip. Fixing the number of elements is expected to result in a more reliable and consistent crack opening behavior, than the common practice of lumping elements [34] far away from the crack tip into a single element. Although computing time may be reduced in the lumping procedure, sharp changes in the crack opening loads at certain distance are sometimes reported [23]. The initial length of the 40 bar elements in region $\mathrm{B}$ is based on the opening displacements of the fictitious crack surfaces at the peak load of the first cycle, while the length of the 60 bar elements in region $C$ is initially set to zero and continually updated with crack growth.

\section{- Model geometry and material properties}

A conventional rectangular center-cracked plate (CCP) subjected to far field tension has been considered for the present analyses, with the dimensions being, length, $L^{\prime}=250.0 \mathrm{~mm}$, width, $W^{\prime}=75 \mathrm{~mm}$, thickness $(B)$ of $12 \mathrm{~mm}$ and half initial crack length, $a_{o}=8.0 \mathrm{~mm} \mathrm{[10,}$ 29, 36]. The material properties chosen are typical of damage tolerant aerospace aluminium alloys, e.g., AA 2024-T351 and 2024A-T351, corresponding to Young's modulus, $E=74 \mathrm{GPa}$, Poisson's ratio, $\quad v=0.33$. Yield stress $\left(\sigma_{y}\right)$ and ultimate tensile strength $\left(\sigma_{U T S}\right)$ along with chemical compositions of AA 2024-T351 and 2024A-T351 are shown in Tables 1 and 2 [36, 39].

\section{- $\quad$ FE modelling}

Essentially equivalent procedures of $\mathrm{FE}$ modelling from $[9,10,29,40,41]$ are followed for modelling fatigue crack growth under variable amplitude loading conditions. In addition to the material properties mentioned above, hardening modulus (bilinear model), $H=$ $0.07 E$ is adopted [9, 42]. [9] reported only a slight increase in closure levels with decreasing hardening modulus (from $0.07 E$ to $0.035 E$ ), consistent with the 


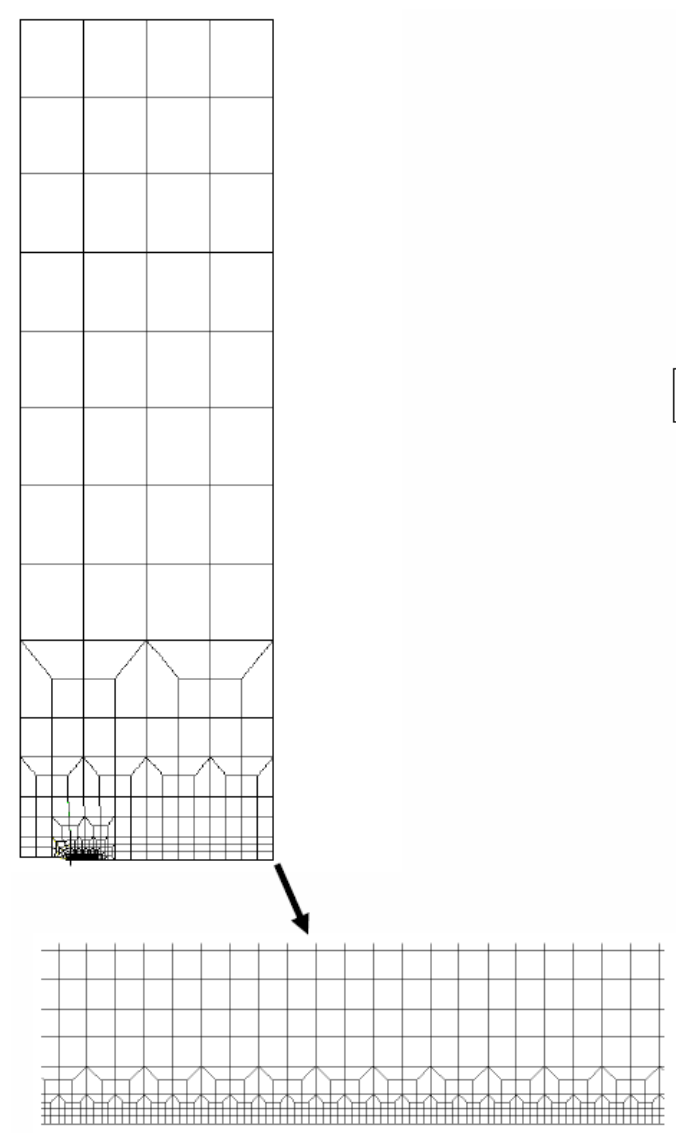

Fig. 2c. i) Typical finite element mesh of one half of the CCP specimen used for the analysis ( 4000 four noded isoparametric quadrilateral elements) and ii) a close-up mesh along the crack propagation direction.

observed lower crack opening associated with lower hardening modulus.

Due to symmetry, only one-quarter of the panel is modelled (Fig. 2c). A typical FE mesh consisted of $\sim 3700$ four-noded quadrilateral isoparametric elements. Selective reduced integration is used to prevent meshlocking and to provide an accurate solution for incompressible material behavior [43]. As the accuracy of near-tip zone modelling is governed by the local element size [44] no appreciable gain in accuracy is expected with the use of higher order elements, such as eightnoded quadrilaterals. Moreover, the use of higher order elements would be computationally expensive. No special crack-tip elements were employed, as the nature of the near-tip field singularity at the tip of a propagating fatigue crack with closure is not well understood [42, 45, 46]. While singular elements for ductile fracture problems are reported to predict stresses which are too large and strains which are too small [47], some researchers [48-50] have attempted to capture near-tip field using special singular elements; however, this approach is inappropriate as the closure phenomenon itself changes the form of crack-tip field [51]. The requirement for crack propagation with retention of prior deformation further constrains the choice of crack tip elements in this work. A typical crack tip element size $\left(L_{e}\right)$ along the propagation path was set at $2 \mu \mathrm{m}$, which is approximately onethirteenth of the plane strain plastic zone size investigated (for $\Delta K=12 \mathrm{MPa} \mathrm{m}^{1 / 2}$ and $R=0.1$ ) as given by [52], thus satisfying the criterion suggested by [44], in keeping with the analyses reported by [9]. The crack propagation algorithms considered here employed the 'spring' type boundary conditions following those of [9, 40, 44, $53,54]$. Opposite nodes along the planned crack propagation path are initially held by two very short linear spring elements. The first spring has a very high stiffness in tension and no stiffness in compression, while the second has very high stiffness in compression and no stiffness in tension. The compressive spring stiffness acts normal to the crack face, preventing interpenetration without affecting the shear displacement of the crack faces. Spring stiffness $\left(k_{\mathrm{s}}\right)$ values of $7.4 \times 10^{8} \mathrm{~N} / \mathrm{m}$ were previously investigated to be sufficiently high to give consistent reasonable crack behavior [9]. Cracks were allowed to propagate one element at a time by releasing the tension spring at maximum load. Crack closure $\left(K_{c} / K_{\max }\right)$ levels were assessed by monitoring the forces in the compression springs in the crack wake. Details of this FE process are given in [29]. In the first instance the analyses were performed for $\Delta K_{(B L)}=12.0$ $\mathrm{MPa} \mathrm{m}^{1 / 2}, R=0.1$, and $\% O L=50,75$ and 100 (but identical for each OL). Overload spacing ranged from $0.136 r_{p(B L)}$ to $25.97 r_{p(B L)}$. Results are presented for single overload first, and subsequently for dual and multiple overloads.

\section{- Crack closure experiments}

Center-crack tension (CCT) specimens were tested at a stress ratio $(R)$ of 0.1 . Side-grooved specimens (corresponding to a reduction in section of $20 \%$, with an internal angle of $30^{\circ}$ ) were used to evaluate stress state effects on crack closure measurements. Stress intensity factors in side-grooved samples were obtained using the multiplicative factor $\left(B / B_{n}\right)^{1 / 2}$ on the $K$ values for a nonside grooved sample of thickness of $B$, where $B$ and $B_{n}$ are the gross thickness and net thickness after sidegrooving, respectively [55]. The alignment of the specimens was carefully checked and adjusted for all tests with four strain gauges on the specimen surfaces. Conventional load shedding was used to obtain baseline $d a / d N \sim \Delta K$ curves. The potential drop (PD) technique was used to monitor crack length and control the fatigue tests automatically.

To obtain detailed crack closure information, a crack mouth clip gauge was used to obtain conventional compliance curves (and thus 'global' closure information), along with arrays of near-tip strain gauges with a spacing of $2 \mathrm{~mm}$ (along the crack growth direction) to obtain 


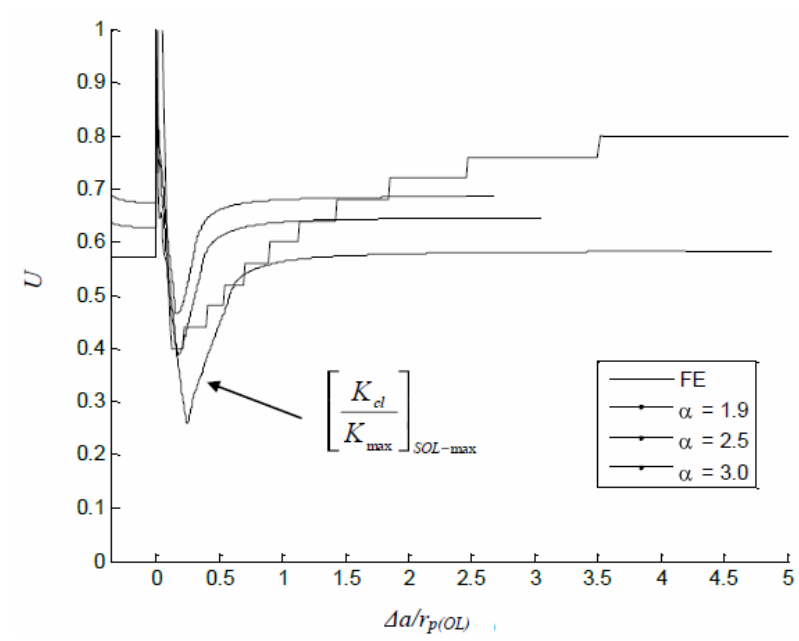

Fig. 3. Comparison of FE and strip yield results for single overloads in terms of closure effects, $\Delta K_{(B L)}=12.0 \mathrm{MPa} \mathrm{m}^{1 / 2}, R=0.1, \% O L=100$.

local crack closure levels. A gap of $1 \mathrm{~mm}$ was set between the edge of the strain gauges and the crack plane to avoid the influence of plastic deformation. Gauge position effects ahead of and behind the crack tip (along the crack growth direction) were studied by sampling several strain gauges simultaneously. Based on compliance curves obtained from crack mouth clip gauges and neartip strain gauges, a systematic assessment of closure measurements was made by a variety of non-subjective methods. Curve fitting methods based on a combination of linear and quadratic functions were used to get closure measurements [35, 36, 39].

\section{Results and discussion}

\subsection{Single overloads}

\subsubsection{Crack closure comparison}

\section{- Effect of constraint factor, $\alpha$}

Fig. 3 shows an example comparison of closure variation between strip yield $\mathrm{r}$ and $\mathrm{FE}$ results for $\Delta K_{(B L)}=12.0$ MPa $\mathrm{m}^{1 / 2}, R=0.1, \% O L=100$. Strip yield results are plotted for different values of $\alpha(=1.9,2.5$ and 3.0). There is an increase in closure levels both in preoverload (i.e., constant amplitude conditions) and postoverload transient, with increasing $\alpha$. An $\alpha$ value of 2.5 predicts a peak-overload transient close to the FE value, although a shorter transient is obtained (i.e., it returns to the baseline closure levels more rapidly). Hence, for all the comparison with FE results an $\alpha$ value of 2.5 is used.

\section{- Effect of overload ratio (\%OL)}

The response to the $\% O L$ variation for both strip yield and FE models is shown in Fig. $4\left(\Delta K_{(B L)}=12.0 \mathrm{MPa}\right.$ $\left.\mathrm{m}^{1 / 2}, R=0.1, \alpha=2.5\right)$. Both models can predict close agreement of the peak-closure transients for $100 \% \mathrm{OL}$; however, the FE modelling is seen to be rather more sensitive to overload level, particularly in terms of the lowest \%OL shown in Fig. 4.

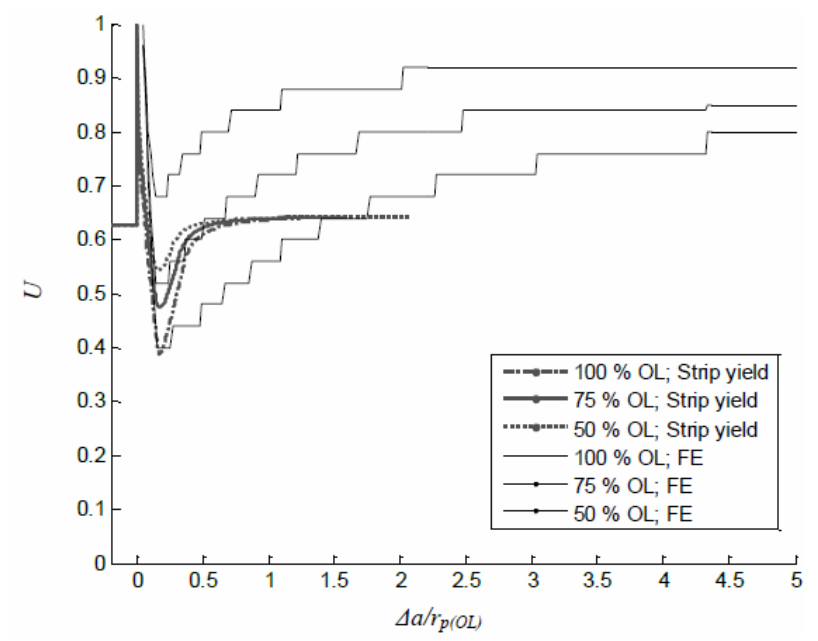

Fig. 4. Comparison of FE and strip yield closure level variation, $\Delta K_{(B L)}$ $=12.0 \mathrm{MPa} \mathrm{m}^{1 / 2}, R=0.1, \alpha=2.5$.

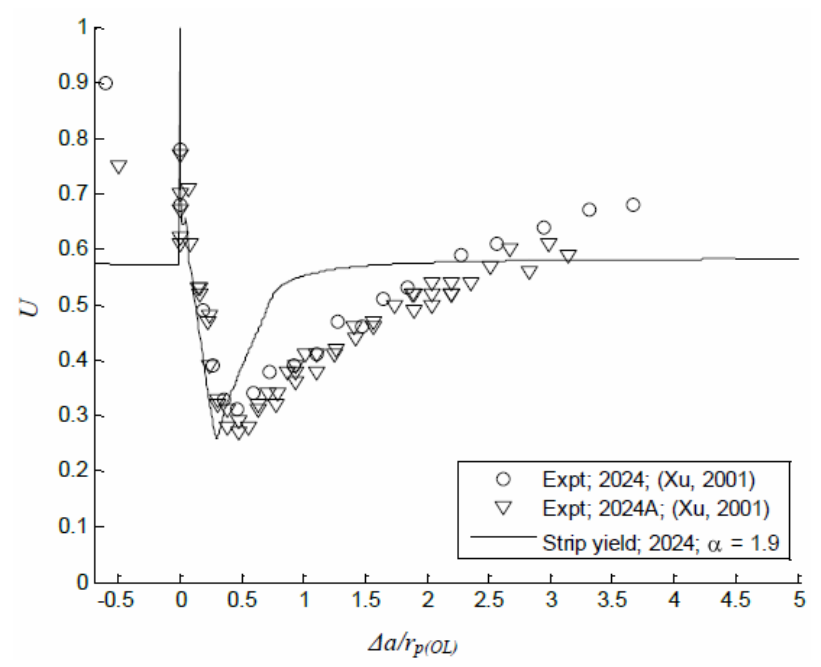

Fig. 5. Comparison of strip yield and experimental closure results, $\Delta K_{(B L)}=12.0 \mathrm{MPa} \mathrm{m}^{1 / 2}, R=0.1, \% O L=100$.

It may be seen that by manipulation of the $\alpha$ parameter some control over the qualitative agreement of the models is achieved, although it is evident that the details of the post overload transient shape cannot be 'resolved': e.g., equivalent transient peak levels may be achieved for one $\alpha$ value, while a more comparable transient length may require higher $\alpha$. Overall, it both (strip yield and FE) modelling methods are of course only approximations of the processes that may occur in reality, particularly for the strip yield approach, where the formulation is fundamentally for plane stress deformation conditions. Further consideration of the validity and choice of modelling approach, and associated fitting parameters (such as $\alpha$ ), is considered in relation to experimental crack closure data below

\section{- Experimental and strip yield modelling results}

Comparison of strip yield and experimental closure levels is shown in Fig. $5\left(\Delta K_{(B L)}=12.0 \mathrm{MPa} \mathrm{m}{ }^{1 / 2}, R=\right.$ $0.1, \% O L=100$ ). With an $\alpha$ value of 1.9 (which is 


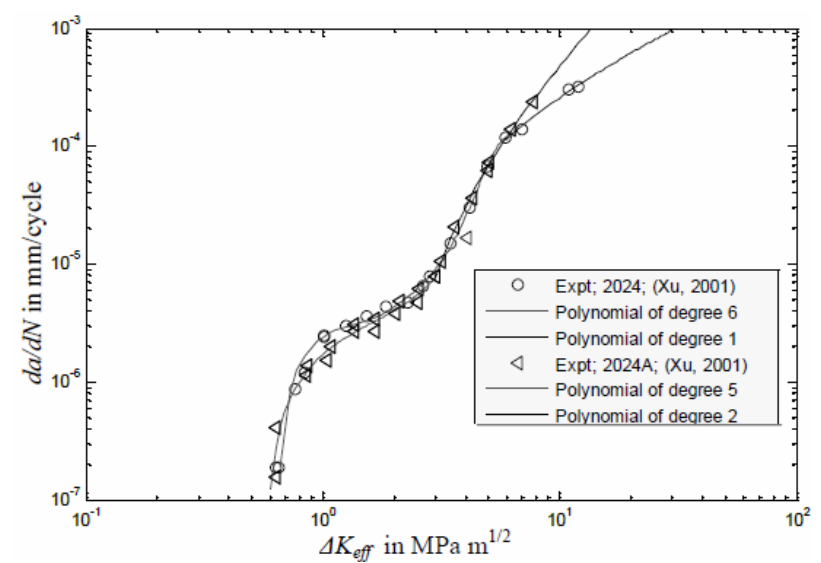

Fig. 6. Intrinsic crack growth behaviour and their approximations through curve fitting, $R=0.1$.

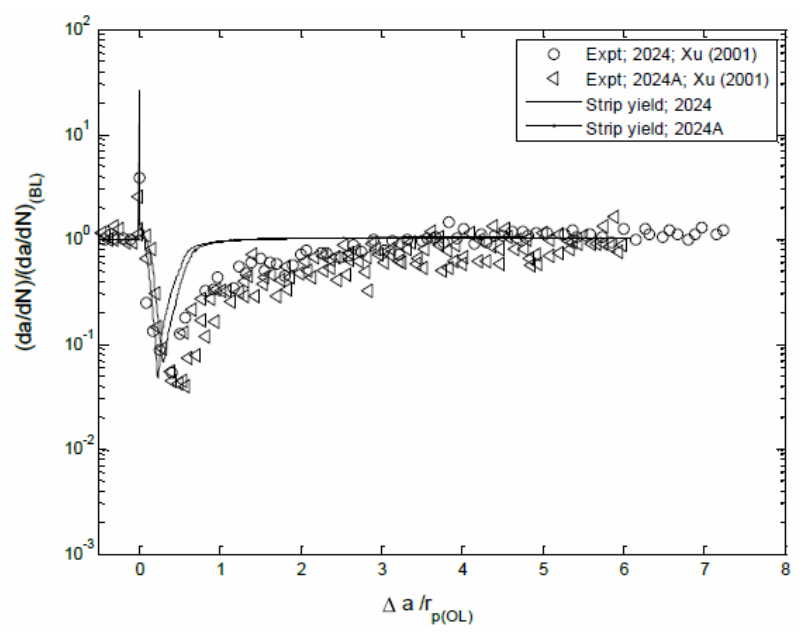

Fig. 7. Comparison of normalised experimental $(\mathrm{Xu}, 2001)$ and predicted growth rates $\left((d a / d N) /(d a / d N)_{(B L)}\right), \Delta K_{(B L)}=12.0 \mathrm{MPa} \mathrm{m}^{1 / 2}, R=$ $0.1, \% O L=100$

lower than that obtained for comparison with FE results), it can be seen that experimental peak overload closure levels are well predicted by the strip yield model. For subsequent comparison with experimental results, an $\alpha$ value of 1.9 has been adopted in the strip yield model.

\subsubsection{Growth rate comparisons $(d a / d N)$}

Having identified the possibility of modelling overload transients purely in PICC terms, it is clearly valuable to consider the accuracy of the predictions against a range of loading conditions. In this respect the results of [35] are again of interest in providing post-overload crack growth rates for $12.0 \mathrm{MPa} \mathrm{m}^{1 / 2}$, and $\% O L$ of 50 and 100: crack closure data for the lower $\Delta K_{(B L)}$ and $\% O L$ values were considered unreliable by $\mathrm{Xu}$, however, as even near-tip compliance changes become hard to detect at lower load levels. Crack growth rates for these alternative load conditions are, however, available, and may of course be considered the more important parameter to predict than crack closure levels in themselves.

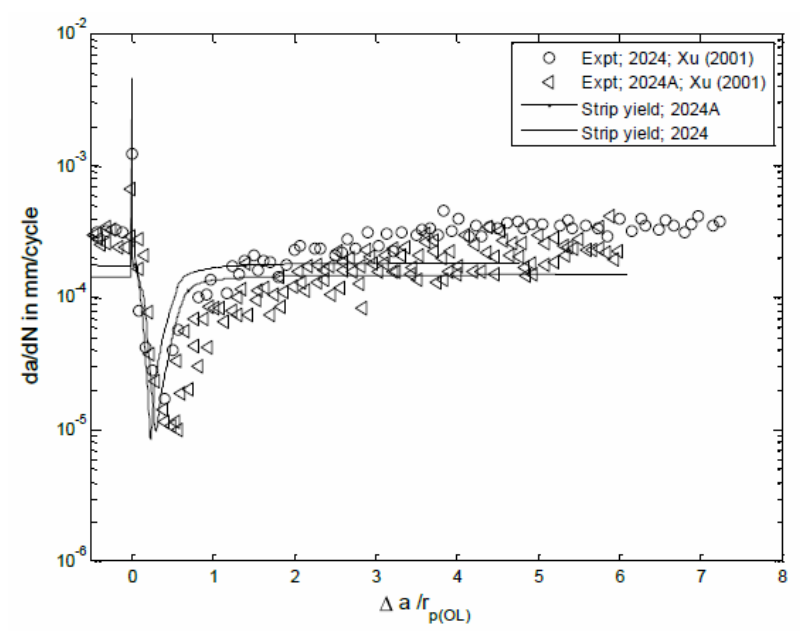

Fig. 8. Comparison of experimental $(\mathrm{Xu}, 2001)$ and predicted growth rates $(d a / d N), \Delta K_{(B L)}=12.0 \mathrm{MPa} \mathrm{m}^{1 / 2}, R=0.1, \% O L=100$.

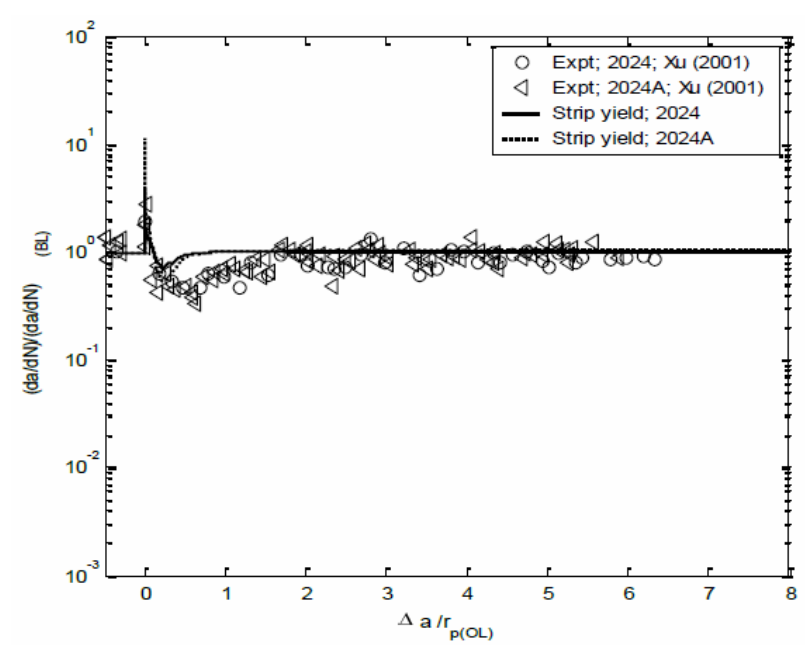

Fig. 9. Comparison of normalised experimental $(\mathrm{Xu}, 2001)$ and predicted growth rates $\left((d a / d N) /(d a / d N)_{(B L)}\right), \Delta K_{(B L)}=12.0 \mathrm{MPa} \mathrm{m}^{1 / 2}, R=$ $0.1, \% O L=50$.

In the following sections, predicted growth rates from strip yield model and experiments will be shown. Growth rates $(d a / d N)$ are obtained from experimental $d a / d N$ vs $\Delta K_{\text {eff }}$ curves as shown in Fig. 6, obtained under constant amplitude loading conditions [35]. Growth rates corresponding to each material are approximated by fitting piecewise polynomial curves, as shown in Fig. 6 (two polynomial curves are used for each material). Using the polynomial curves, predicted $d a / d N$ is obtained using the overload model $\Delta K_{\text {eff }}$ predictions.

$$
\text { - } \Delta K_{(B L)}=12.0 \mathrm{MPa} \mathrm{m}^{1 / 2}, R=0.1, \% O L=100
$$

Fig. 7 shows a comparison of strip yield normalized growth rate predictions with experimental results from [35] for $\Delta K_{(B L)}=12.0 \mathrm{MPa} \mathrm{m}^{1 / 2}, R=0.1, \% O L=100$. Strip yield and experimental results are plotted for both 2024 and 2024A alloys. It can be seen in Fig. 7 that the strip yield models predict minimum growth rates of about $6 \%$ and $4 \%$ of the baseline growth rates for 2024 and $2024 \mathrm{~A}$, respectively, which are clearly of the same 


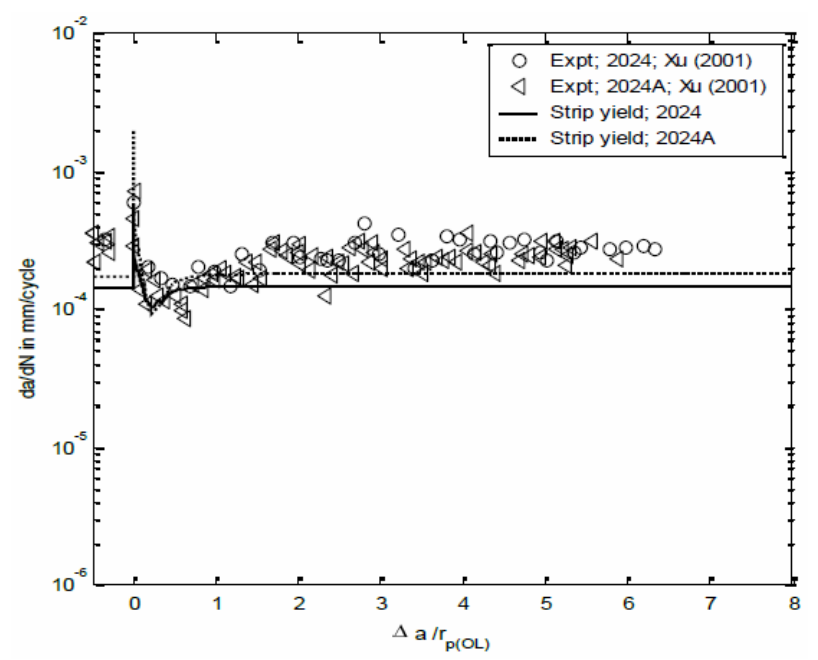

Fig. 10. Comparison of experimental $(\mathrm{Xu}, 2001)$ and predicted growth rates $(d a / d N), \Delta K_{(B L)}=12.0 \mathrm{MPa} \mathrm{m}^{1 / 2}, R=0.1, \% O L=50$.

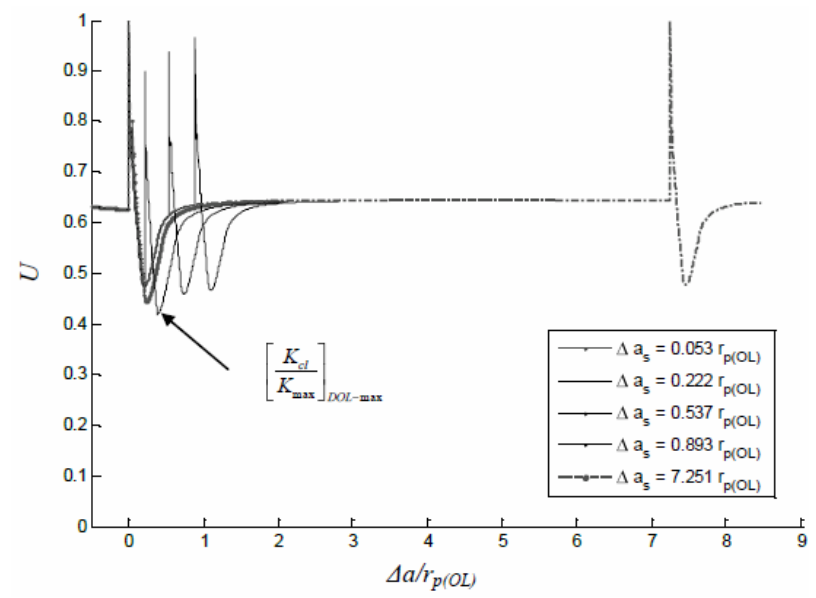

Fig. 11. Effect of overload spacing on closure predicted by strip yield approach, $\Delta K_{(B L)}=12 \mathrm{MPa} \mathrm{m}^{1 / 2}, \quad R=0.1$.

order as the experimental values. The affected distance is about $50 \%$ of the experimental results; however, consistent with the relatively short closure transients associated with strip yield models as discussed previously. Such an underestimate of plane strain overload transient distances has been identified previously [35], with strip yield modelling being shown to give rather more accurate descriptions of plane stress overload transient distances, consistent with the plane stress formulation.

While normalized growth rate plots (as in Fig. 7) are clearly able to compare overload growth rates in relation to the baseline rates, it is possible that they may 'hide' differences in the actual growth rate. Fig. 8 shows the predicted growth rates of the strip yield models with experimental results from [35]. Baseline growth rates predicted by strip yield models are slightly lower than the experimental results. Overall, however, for the conditions shown, overload growth predicted by strip yield and analytical models appears to be of the correct order.

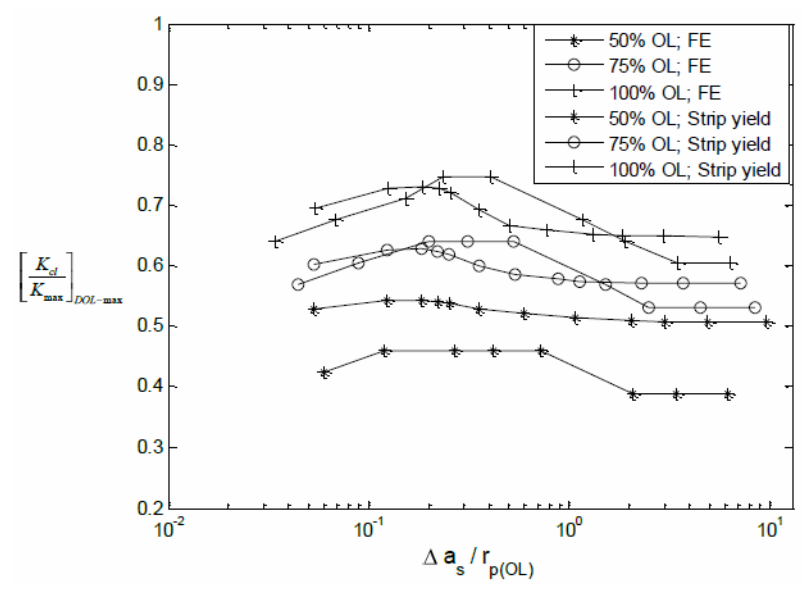

Fig. 12. Variation of maximum closure levels with OL spacing for different OL ratios $\left(\Delta K_{(B L)}=12 \mathrm{MPa} \mathrm{m}^{1 / 2}, \quad R=0.1\right)$.

At this point it is valuable to recognize again the degree of fitting involved in the strip yield method. The choice of $\alpha$ in Figs. 7 and 8 in the strip yield model is giving an acceptable approximation of baseline $d a / d N$ and peak overload transient effects for experiments that are designed (via sample side grooving in particular) to be plane strain dominated.

$$
\text { - } \Delta K_{(B L)}=12.0 \mathrm{MPa} \mathrm{m}^{1 / 2}, R=0.1, \% O L=50
$$

To assess the effect of lowering overload ratio to $50 \%$, a comparison of normalized growth rates is shown in Fig. 9. Experimental minimum growth rates for both alloys are approximately $50 \%$ of the baseline growth compared to the $100 \%$ OL case, consistent with the reduction in overload level. Predicted normalized minimum growth rates from both strip yield appear to agree well the experimental results, although the strip yield model shows shorter transients once more. Predicted and experimental growth rates are again plotted without normalization in Fig. 10.

\subsection{Double overloads}

\subsubsection{Crack closure comparison}

Comparisons are made with FE results only due to the absence of comparable experimental data.

\section{- Crack closure - overload spacing effects}

Fig. 11 shows the variation of $U$ plotted against normalized crack length $\left(\Delta a / r_{p(B L)}\right)$ for $\Delta K_{(B L)}=12 \mathrm{MPa} \mathrm{m}^{1 / 2}$, $R=0.1, \% O L=75$. In this figure, plots corresponding to five overload spacings $\left(\Delta a_{s}=0.05,0.22,0.53,0.89\right.$ and $\left.7.2 r_{p(O L)}\right)$ are shown. The first overload is located at $\left(\triangle a / r_{p(O L)}\right)=0.0$. As in the FE results see [29] there is an increase in the maximum closure levels associated with the second overload being a short distance $\left(\sim 0.22 r_{p(O L)}\right)$ from the first overload location.

In Fig. 12, the maximum closure levels corresponding to the second overload $\left(\left[K_{c l} / K_{\max }\right]_{D O L-\max }\right)$ are plotted 


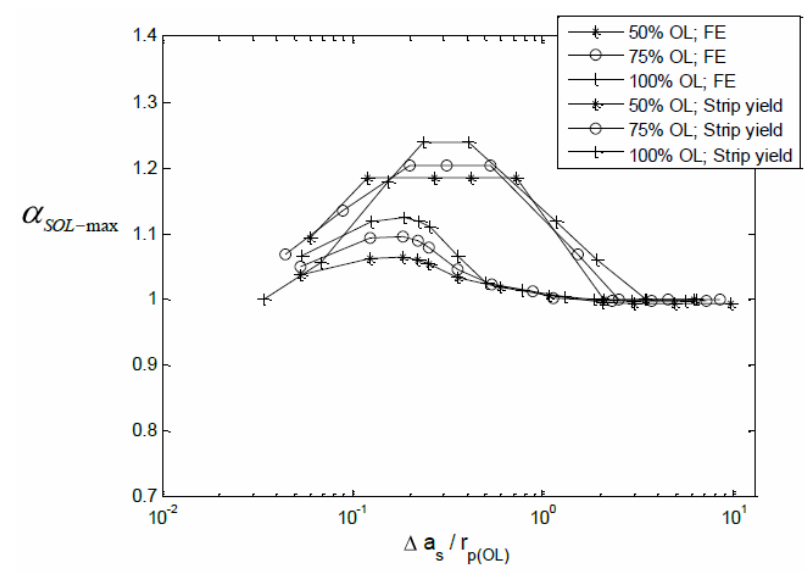

Fig. 13. Variation of $\alpha_{\text {SOL-max }}$ with OL spacing for different OL ratios $\left(\Delta K_{(B L)}=12 \mathrm{MPa} \mathrm{m}^{1 / 2}, \quad R=0.1\right)$.

for $\% O L=50,75$ and $100\left(\Delta K_{(B L)}=12 \mathrm{MPa} \mathrm{m}^{1 / 2}, \quad R=\right.$ 0.1 ) for both FE and strip yield models. $\left[K_{c} / K_{\max }\right]_{D O L-\max }$ is plotted against $\Delta a_{s} / r_{p(O L)}$. An increase in $\left[K_{c l} / K_{m a x}\right]_{D O L-}$ max values with increase in $\% \mathrm{OL}$ is again seen. In contrast to the FE results which suggests an increasing zone of maximum retardation span with decreasing \%OL, strip yield models predict a consistent maximum retardation point at approximately $\Delta a_{s}=0.29 r_{p(O L)}$ for all the overloads modelled. Fig. 13 shows the variation of $\alpha_{S O L-\max }$ $\left(=\left[K_{c l} / K_{\max }\right]_{D O L-\max } /\left[K_{c l} / K_{\max }\right]_{S O L-\max }\right.$, i.e., ratio of maximum closure levels of double (DOL) and single (SOL) overloads) with $\Delta a_{s} / r_{p(O L)}$. It can be observed from Fig. 13 that there is an increase of approximately $6 \%, 9.5 \%$ and $12.5 \%$ in the maximum closure levels when compared to the single overload conditions (expressed in terms of $\alpha_{S O L-\max }$ ) for $50 \%, 75 \%$ and $100 \%$ OL respectively, i.e., somewhat lower than the corresponding FE results but of a similar order. For the OLs considered, $\alpha_{S O L-\max }$ drops to unity after at about $2 r_{p(O L--a t}$ the lower end of the range suggested by the FE models.

The implication that the primary effect of a previous load transient on a subsequent load event may be expressed through the instantaneous crack closure levels (and the consequent influence on forward and reverse deformation processes) is clearly of interest as this may provide a valuable simplification of any engineering design approach that may be developed. In the first instance it is clearly valuable to further consider the current modelling results in relation to available experimental data.

\subsubsection{Growth rate interaction}

In the previous sections, closure response during double overloads excursion has been studied using two numerical modelling approaches, FE and strip yield: however, to the best of authors' knowledge, corresponding experimental closure studies have not been widely reported previously. Experimental work carried out by $[12,13]$ may, however, provide a valuable insight into the growth rate interaction of double overloads.

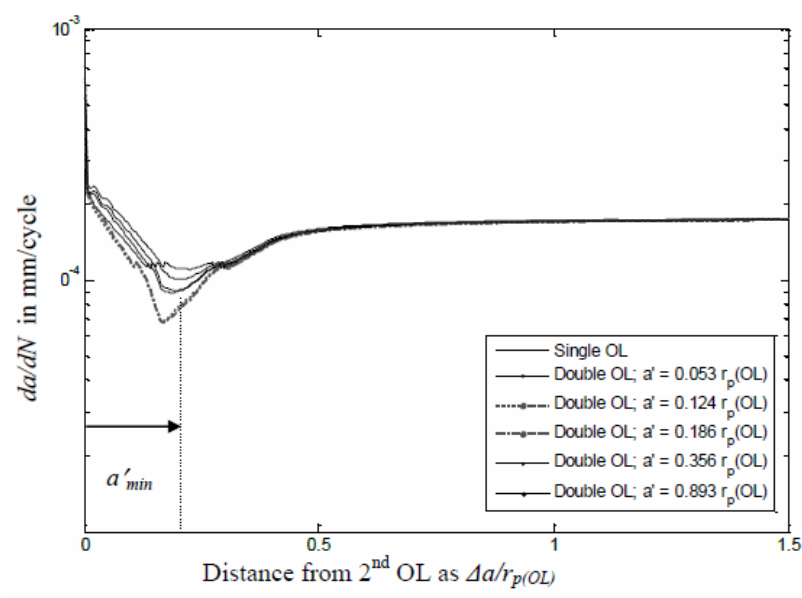

Fig. 14. Predicted crack growth rate variations following 2 OLs , $\Delta K_{(B L)}$ $=12.0 \mathrm{MPa} \mathrm{m}^{1 / 2}, \quad R=0.1, \% \mathrm{OL}=75$ (strip yield method $)$.

The crack closure results from FE and strip yield type models have been used to predict crack growth rates using the method described in Section 3.1.2 (i.e., using

previously determined $d a / d N \mathrm{Vs} \Delta K_{\text {eff }}$ curves from constant amplitude tests). Predicted plane strain growth rates for single overload and double overloads are plotted, $\Delta K_{(B L)}=12.0 \mathrm{MPa} \mathrm{m}{ }^{1 / 2}, \quad R=0.1, \% O L=75$, for strip yield methods in Fig. 14 (minor discontinuities in the predicted $d a / d N$ curves are due to the approximations in the curve fitting approach for $d a / d N$ vs $\left.\Delta K_{\text {eff }}\right)$. The minimum in $2^{\text {nd }}$ overload growth rates (and hence maximum interaction) occur when the two overloads are separated by $a_{\text {min }}^{\prime}$ (i.e., the amount of crack extension to reach the minimum growth rate during a single overload), consistent with the finding from Mills and Hertzberg. The predicted $a_{\text {min }}^{\prime}$ values are approximately $0.19 r_{p(O L)}$ strip yield type $\left(0.25 r_{p(O L)}\right.$ for FE models, See [10]. The incidence of the maximum double overload interaction effect occurring when the $2^{\text {nd }}$ overload is applied at the growth rate minimum of the first transient can of course be seen as simply consistent with the consideration of ' $R_{\text {eff' }}$ (effective $R$, due to the influence of the residual deformation of the previous, i.e., $1^{\text {st }}$ overload) influences in the analytical [56] and FE [17] models. If closure is the controlling process in these transients, then the minimum $d a / d N$ point of the single overload will correspond to the maximum closure condition of the first overload. Any transient applied now will experience the least reversed plastic deformation during unloading and leave the largest residual lump in the crack wake.

\subsection{Multiple overloads}

Fig. 15 shows variations of $U$ with normalized crack length $\left(\Delta a / r_{p(O L)}\right)$ for $\Delta K_{(B L)}=12 \mathrm{MPa} \mathrm{m} \mathrm{m}^{1 / 2}, \quad R=$ $0.1, \% O L=50$, obtained from strip yield analysis. The first overload is located at $\Delta a / r_{p(O L)}=0.0$ and subsequent 


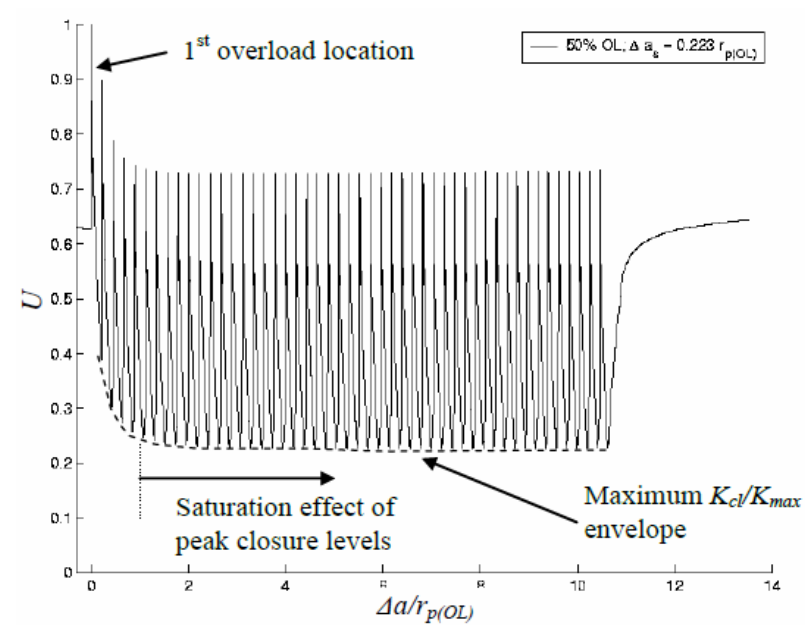

Fig. 15. Typical closure variation of a crack subjected to periodic overloads, $\Delta K_{(B L)}=12 \mathrm{MPa} \mathrm{m}^{1 / 2}, R=0.1, \% O L=50$ (Strip yield method).

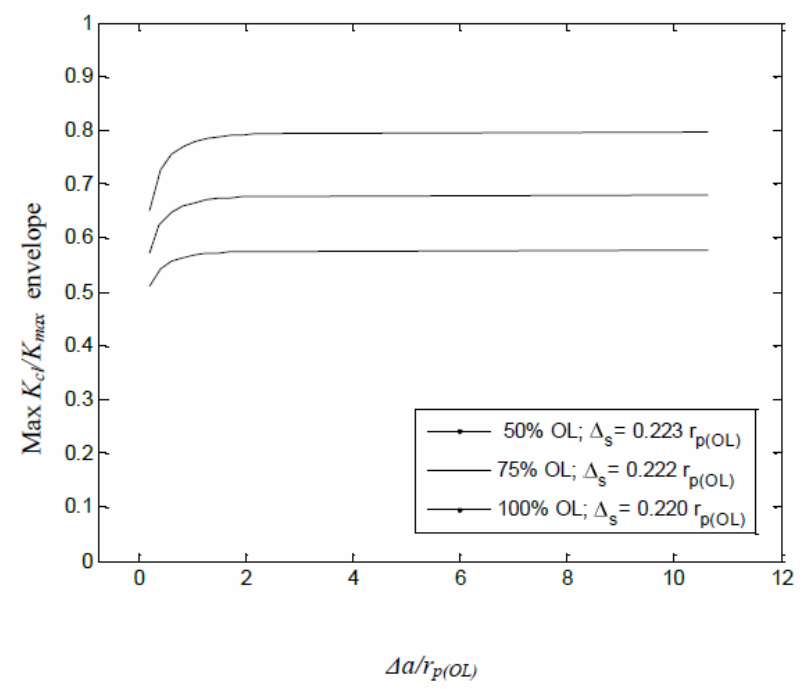

Figure 16: Variation of maximum closure envelope with OL spacing for different $\mathrm{OL}$ ratios, $\Delta K_{(B L)}=12 \mathrm{MPa} \mathrm{m}^{1 / 2}, \quad R=0.1, \% O L=100$ (Strip yield method).

periodic overloads are applied at a spacing, $\Delta a_{s}=0.233$ $r_{p(O L)}$. Increasing severity of peak closure levels can be observed for approximately $1.0 r_{p(O L)}$ from the location of the first overload, after which 'saturation' appears to occur. In the first instance an envelope passing through maximum closure levels can be defined as a measure of closure severity as the crack propagates. The variation of maximum closure envelopes for $\% O L=50,75$ and 100 is plotted in Fig. 16 for equal overload spacing of $\Delta a_{s} \sim$ $0.22 r_{p(O L)}$ in all the three cases. In Fig. 16 there is a rise in the maximum closure envelope as $\% O L$ increases; however, the envelopes appear to saturate ('saturation effect') at $\Delta a=1.0 r_{p(O L)}$ in all three cases, suggesting that the saturation process is primarily controlled by overload deformation. The present results agree qualitatively with the experimental findings of [28] on 2024 aluminium alloy subjected to periodic overloads (varying $\% O L$ and $\Delta N_{s}$ ), where the authors reported a stabi

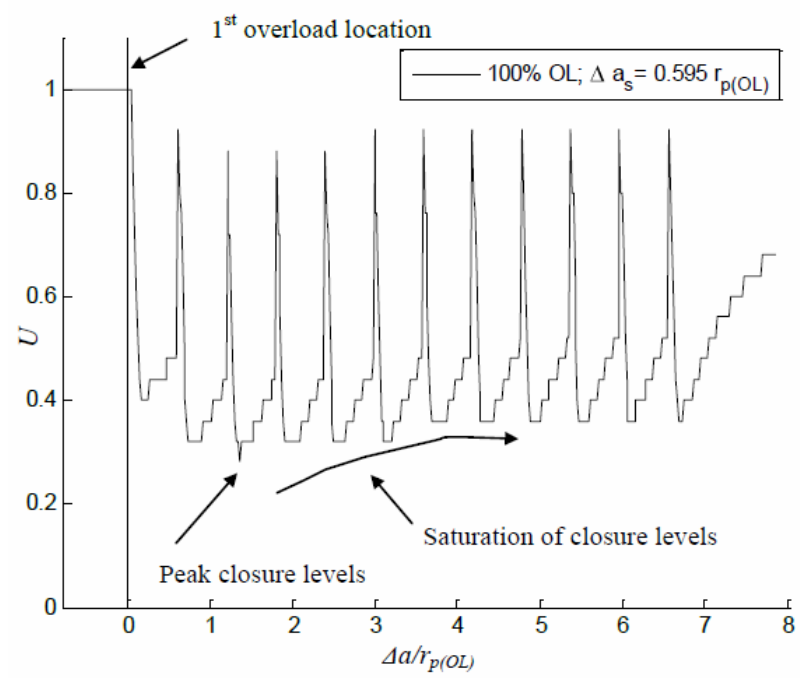

Fig. 17. Typical closure variation of a crack subjected to periodic overloads, $\Delta K_{(B L)}=12 \mathrm{MPa} \mathrm{m}^{1 / 2}, \quad R=0.1, \% O L=100$ (FE method).

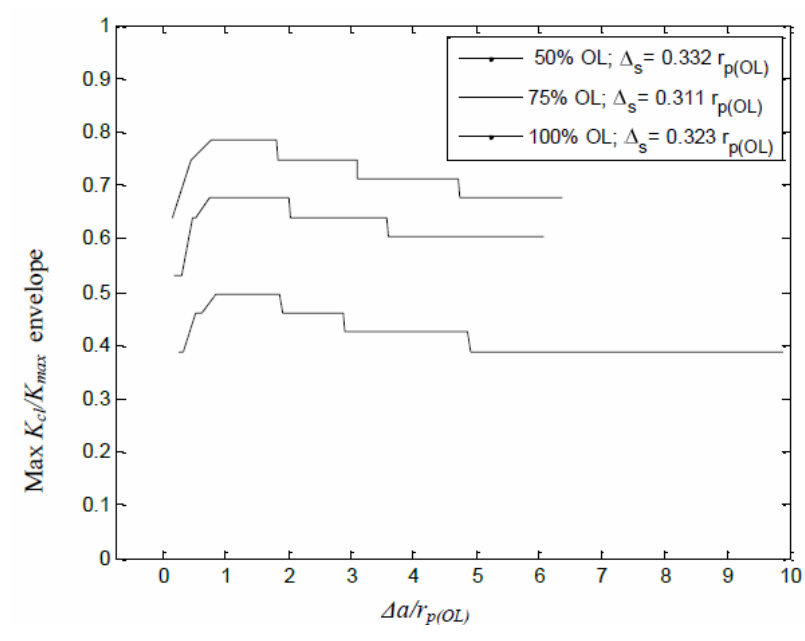

Fig. 18. Variation of maximum closure envelope with OL spacing for different $\mathrm{OL}$ ratios, $\Delta K_{(B L)}=12 \mathrm{MPa} \mathrm{m}^{1 / 2}, \quad R=0.1, \% O L=100$ (FE method).

lized value of crack opening loads as crack growth proceeds.

Variation of $U$ with crack length from FE analysis is plotted against normalized crack length, $\Delta a / r_{p(O L)}$, in Fig. 17 for the conditions mentioned above. The initial variation of $U$ with crack length is seen to follow the results from the strip yield models. An increase of peak closure level is seen: this is, however, followed by a decrease to a lower saturation level ('peak and saturation effect'). The presence of the 'peak and saturation effect' in the maximum closure envelope is not shown by the strip yield models (both approaches only show a 'saturation effect'). Fig. 18 shows the variation of maximum closure envelopes for $\% O L=50,75$ and $100\left(\Delta a_{s} \sim 0.3\right.$ $\left.r_{p(O L)}\right)$. A rising pattern of maximum closure levels is seen with increasing $\% O L$, which is consistent with the findings from strip yield models. 'Peak and saturation 


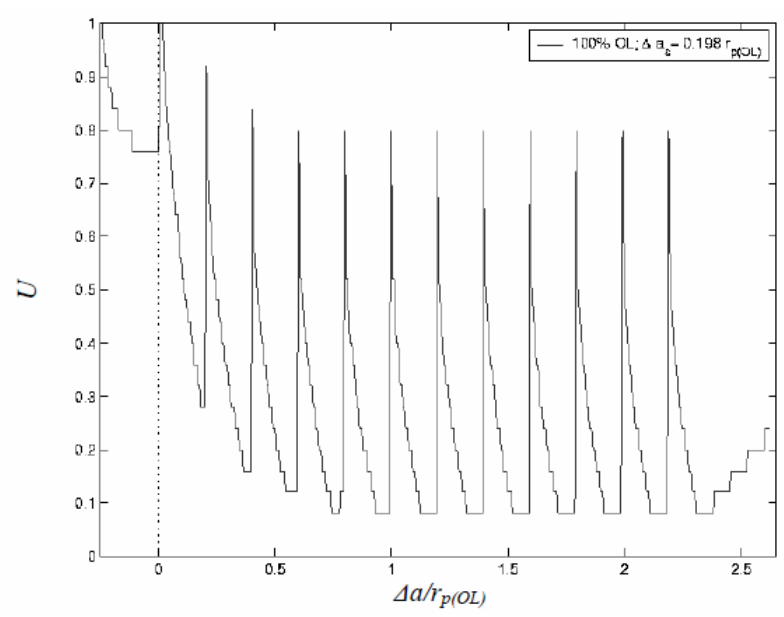

Fig. 19. Typical closure variation of a crack subjected to periodic overloads, $\Delta K_{(B L)}=12 \mathrm{MPa} \mathrm{m}^{1 / 2}, \quad R=0.1, \% O L=100$, plane stress $(\mathrm{FE}$ method).

effect' on maximum closure envelope are, however, seen consistently for all \%OLs. In all cases, the peak of the maximum closure levels appear to occur at about 1.0 $r_{p(O L)}$ from the location of the first overload.

The appearance of a 'peak and saturation effect' in the peak closure levels due to periodic overloads in plane strain may then be explained by understanding the material movement during fatigue crack propagation. [29] notes that for constant amplitude plane strain conditions, material cannot move in the thickness direction and the discontinuous contact near the pre-crack tip results from the transverse (in plane) movement of material near the pre-crack tip (causing a transient lump). It may be noted that diminishing closure effects (approaching saturation) following peak closure levels may then arise from the requirement to keep the material moving forward, in plane. For subsequent overloads, it may intuitively be noted that having drawn material forward along the crack wake for one overload, a closely spaced additional overload will encounter increased resistance in drawing more material forward from the crack wake. This follows through to the logical 'end point' where the overload spacing becomes vanishingly small and growth is simply occurring at a consistent $\Delta K_{(O L)}$; for plane strain conditions results in chapter 3 indicate that closure levels must tend towards zero under sustained crack growth (after an initial transient at the undeformed pre-crack tip). The requirement for transverse movement of material does not arise for plane stress conditions (material movement occurs through thickness), and hence a 'peak and saturation' effect should not occur for plane stress cracks subjected to periodic overloads if the above explanation is correct. Fig. 19 plots the variation of $U$ with normalized crack length $\left(\Delta a / r_{p(O L)}\right)$, for sustained periodic overloads under plane stress conditions $\left(\Delta K_{(B L)}=12\right.$ $\left.\left.\mathrm{MPa} \mathrm{m}^{1 / 2}, \quad R=0.1, \% O L=100,\right) \Delta a_{s} \sim 0.196 r_{p(O L)}\right)$. A simple saturation of peak closure levels is seen, consistent with proposed dependence of plane strain period- ic transient behavior on transverse material movement. It may then be seen that the evolution of multiple transient effects in plane strain requires consideration of at least two phenomena: the 'effective $R$-ratio' influence of previous transient, and, increasing transverse constraint. These act in opposing senses in terms of the severity of ongoing closure transients. The absence of 'peak + saturation' effect in the strip yield modelling may also be seen as entirely consistent with the model's fundamental plane stress character, where in-plane constraint effects must be minimal.

\section{Conclusions}

Variable amplitude fatigue crack propagation has been studied for single, double and multiple overload transients using the popular 'strip yield' (FASTRAN type) approach, with comparisons with recently published finite element and experimental results. The results are summarised below.

1. Double overload closure behavior is functionally similar for the two modelling (i.e. finite element and strip yield models) approaches used.

2. The strip yield type approach is seen to be fundamentally limited by choice of $\alpha$ and corresponding ability to treat baseline closure effects.

3. Plasticity induced crack closure can be used to explain much of the OL transient behavior investigated experimentally.

4. Under repeated overloads, an important functional difference is seen between FE and the analytical and strip yield models. This has been linked to the absence of in-plane constraint in the strip yield model, which is seen to have a distinct decreasing influence on on-going closure effects.

\section{Acknowledgment}

This work was supported by Airbus, UK and EPSRC, UK. Helpful discussions with Drs. RA Collins from Airbus, UK, and J-C Ehrstrom from Alcan, France are gratefully acknowledged.

\section{References}

[1] M. Skorupa, Load interaction effects during fatigue crack growth under variable amplitude loading - a literature reviews. Part I: empirical trends, Fatigue and Fracture of Engineering materials and Structures 21 (1998) 987-1006.

[2] F. Ellyin, and J. Wu, A numerical investigation on the effect of an overload on fatigue crack opening and closure behaviour, Fatigue and Fracture of Engineering Materials and Strutures 22 (1999) 835-847.

[3] Al. Th. Kermanidis, and Sp. G. Pantelakis, Fatigue crack 
growth analysis of 2024 T3 aluminium specimens under aircraft spectra, Fatigue and Fracture of Engineering Materials and Structures 21 (2001) 699-710.

[4] W. Geary, A review of some aspects of fatigue crack growth under variable amplitude loading, International Journal of Fatigue 14 (1992) 377-386.

[5] H. Bao, and A.J. McEvily, The effect of an overload on the rate of fatigue crack propagation under plane stress conditions, Metallurgical and Materials Transactions A 26A July (1995) 1725-1733.

[6] R. D. Brown, and J. Weertman, Effects of tensile overloads on crack closure and crack propagation rates in 7050 aluminium, Engineering Fracture Mechanics, 10, (1978) 867-878.

[7] W. X. Alzos, A.C. Jr. Skat, and B.M. Hillberry, Effect of single overload/ under load cycles on fatigue crack propagation. ASTM STP 595, (1976) 4160.

[8] K. T. Venkateshwara Rao and R.O. Ritchie, Mechanisms for the retardation of fatigue cracks following single tensile overloads: behaviour in aluminium-lithium alloys, Acta Mettalurgica 36 (1988) 2849-2862.

[9] M. R. Parry, Finite element and analytical modelling of roughness induced fatigue crack closure, PhD thesis, University of Southampton. Southampton, UK (2000).

[10] K.D. Singh, K.H. Khor, and I. Sinclair, Roughness and plasticity induced crack closure effects under single overloads: Finite element modelling, In Acta Materialia 54 (2006) 43934403.

[11] R.P. Wei, T.T. Shih, and J.H. Fitzgerald, Load interaction effects on fatigue crack growth in Ti-6Al-4V alloy, NASA CR2239 (1973).

[12] W.J. Mills, and R.W. Hertzberg, Load interaction effects on fatigue crack propagation in 2024-T3 aluminium alloy, Engineering Fracture Mechanics 8 (1976) 657-667.

[13] W.J. Mills, and R.W. Hertzberg and R. Roberts, Load interaction effects on fatigue crack growth in A514 steel alloy, In Cyclic Stress-Strain and Plastic Deformation Aspects of Fatigue Crack Growth, ASTM STP 637 (1977) 192-208.

[14] M. M. I. Hammouda, S. S. E. Ahmed, M. H. Seleem, and H. E. M. Sallam, Fatigue crack growth due to two successive single overloads, Fatigue and Fracture of Engineering Materials and Structures 21, (1998) 1537-1547.

[15] Y.K. Tur, and O. Varder, Periodic tensile overloads in 2024-T3 Al-Alloy, Engineering Fracture Mechanics 53 (1996) 69-77.

[16] S. Klysz, Pecularities of fatigue crack growth and modifications of the wheeler retardation model, In VII Summer School of Fracture Mechanics, Pokrzywna, Poland, (2001) 85-104.

[17] R. Herper, O. Varder, Elasto-plastic material response of fatigue crack surface profiles due to overload interactions, International Journal of Fatigue 25 (2003) 801-810

[18] N.A. Fleck, Fatigue crack growth due to periodic underloads and overloads, Acta Metallurgica 33 (1985) 1339-1354.

[19] M. Skorupa, Load interaction effects during fatigue crack growth under variable amplitude loading - a literature reviews. Part II: qualititative interpretation. Fatigue and Fracture of Engineering Materials and Structures 22, (1999) 905-626.

[20] A.F. Blom, and D.K. Holm, Load interaction effects on fatigue crack propagation in steels of varying strength, In Role of Fracture Mechanics in Modern Technology, (Editors, C.C. Sih, H. Nisitani, and T. Ishihara), Elsevier Science Publishers B.V., Holland. (1987).

[21] O. Jonas, and R.P. Wei, An exploratory study of delay in fatigue-crack growth, International Journal of Fracture 7 (1971) 116-118.
[22] J.C. Newman, Prediction of crack growth under variableamplitude loading in thin-sheet 2024-T3 aluminium alloys. In Engineering Against Fatigue, University of Sheffield, March (1997).

[23] J.C. Newman, Analyses of fatigue crack growth and closure near threshold conditions for large-crack behaviour, NASA TM 209133 (1999).

[24] R.C. Rice, and R. I. Stephens, Overload effects on subcritical crack growth in austenitic manganese steel. In Progress in Flaw Growth and Fracture Toughness Testing, ASTM STP 536, (1973)95.

[25] S.J. Park, and J.H. Song, Simulation of fatigue crack closure behaviour under variable-amplitude loading by a 2D finite element analysis based on the most appropriate mesh size concept, In Advances in Fatigue Crack Closure Measurements and Analysis, ASTM STP 1343 (1999) 337-348.

[26] S. Zhang, R. Marissen, K. Schulte, K.H. Trautmann, and J. Schijve, Crack-propagation studies on Al-7475 on the basis of constant amplitude and selective variable amplitude loading histories, Fatigue and Fracture of Engineering Materials and Structures 10 (1987) 315-332.

[27] R. P. Wei, and T.T. Shih. Delay in fatigue crack growth. International Journal of Fracture 10, (1974) 77-85.

[28] C.Y. Kim, and J.H. Song, Fatigue crack closure and growth behaviour under random loading, Engineering Fracture Mechanics 49 (1994) 105-120.

[29] K.D. Singh, K.H. Khor, I. Sinclair, Finite element and analytical modelling of crack closure due to repeated overloads, In Acta Materialia 56 (2008) 835-851.

[30] D.S. Dugdale, Yielding of steel sheets containing slits, Journal of Mechanics and Physics of Solids 8 (1960) 100-108.

[31] H.D. Dill, and C.R. Saff, Spectrum Crack Growth Prediction Methods Based on Crack Surface Displacement and Contact Analyses, ASTM STP 595 (1976) 306-319.

[32] B. Budiansky, and J.W. Hutchinson, Analysis of closure in fatigue crack growth, Journal of Applied Mechanics 45 (1978) 267-276.

[33] H. Fuhring, and T. Seeger, Dugdale crack closure analysis of fatigue cracks under constant amplitude loading, Engineering Fracture Mechanics 11 (1979) 99-122.

[34] J.C. Newman, A crack closure model for predicting fatigue crack growth under aircraft spectrum loading, In Methods and Models for Predicting Fatigue Crack Growth under Random Loading, ASTM STP 748 (1981) 53-84.

[35] Y. Xu, Closure assessment and overload transient behaviour in damage tolerant airframe materials, $\mathrm{PhD}$ Thesis, School of Engineering Sciences, University of Southampton. Southampton, UK (2001).

[36] Y. Xu, J. Chen, Li. Jianmin, and Z. Zhu, Improved fatigue and damage tolerant material design for aerospace industry, Journal of Material Science and Technology, 21 (2005) 856862.

[37] J. C. Newman, C.A. Bigelow, and K.N. Sivakumar, Threedimensional elastic-plastic finite element analysis of constraint variations in cracked bodies, Engineering Fracture Mechanics 46 (1993) 1-13.

[38] J.C. Newman, FASTARN II: A fatigue crack growth structural analysis program, NASA TM 104159 (1992).

[39] Y. Xu, P.J. Gregson, and I. Sinclair, Systematic assessment and validation of compliance-based crack closure measurements in fatigue, Materials Science and Engineering A284 (2000) 114-125.

[40] MR. Parry, S. Syngellakis, and I. Sinclair, Numerical modelling of combined roughness and plasticity induced crack 
closure in fatigue, Material Science and Engineering, A291 (2000) 224-34.

[41] N. Kamp, M.R. Parry, K.D. Singh, and I. Sinclair, Analytical and finite element modelling of roughness induced crack closure, Acta Materialia 52 (2004) 343-353.

[42] R.O. Ritchie, W. Yu, A.F. Blom, and D.K. Holm, An analysis of crack tip shielding in aluminium alloy 2124: a comparison of large, small, through-thickness and surface fatigue cracks, Fatigue and Fracture of Engineering Materials and Structures 10 (1987) 343-363.

[43] Hibbiit, Karlson and Sorensen, ABAQUS Theory Manual Version 5.8, Inc., Pawtucket, RI, USA, ABAQUS (1998).

[44] R.C. McClung, and H. Sehitoglu, On the finite element analysis of fatigue crack closure -1 , Basic modelling issues, Engineering Fracture Mechanics 33 (1989) 2, 237-252.

[45] N.A. Fleck, and J.C. Newman, Analysis of crack closure under plane strain conditions, In Mechanics of Fatigue Crack Closure, ASTM STP 982 (1988) 319-341.

[46] R. C. McClung, and D.L. Davidson, High resolution numerical and experimental studies of fatigue cracks, Engineering Fracture Mechanics 39 (1991) 1, 113-130.

[47] H. Liebowitz, and Jr. E.T. Moyer, Finite element methods in fracture mechanics, Computer and Structures 31 (1989) 1, $1-9$.

[48] M. Nakagaki, and S.N. Atluri, Fatigue crack closure and delay effects under mode I spectrum loading: an efficient elastic-plastic procedure. Fatigue Engineering Material Structure 1, (1979) 421-429.

[49] M. Nakagaki, and S.N. Atluri, Elasto-plastic analysis of fatigue crack closure in modes I and II, AIAA 18 (1980) 1110-1117.

[50] X., Zhang, A.S.L. Chang, and G. A. O. Davies, Numerical simulation of fatigue crack growth under complex loading sequences. Engineering Fracture Mechanics 42, (1992) 305321.

[51] R.C. McClung, Finite element analysis of fatigue crack closure: a historical and critical review, In Proceedings of Seventh International Fatigue Crack Conference, Beijing, China 1 (1999) 495-502.

[52] G. R. Irwin, Plastic near a crack and fracture toughness. In Proceedings of the Seventh Sagamore Ordance Materials Conference IV, New York, Syracuse University, (1960) 63-78. [53] J.C. Newman, and H. Armen, Elastic-plastic analysis of a propagating crack under cyclic loading, AIAA Journal 13 (1975) 1017-1023.

[54] H. Andersson, C. Persson, T. Hansson, S. Melin, and N. Jarvstrat, Constitutive dependence in finite-element modelling of crack closure during fatigue, Fatigue and Fracture of Engineering Materials and Structures 27 (2004) 75-87.

[55] S.T. Rolfe, S.R. Novak, American Society for Testing and Materials, Philadelphia, PA, ASTM STP463 (1970) 124-159.

[56] K.D. Singh, K.H. Khor, and I. Sinclair, Roughness and plasticity induced crack closure effects under single overloads: Analytical modelling, In Acta Materialia 54 (2006a) 44054414. 